\title{
Da cordialidade à brega: \\ o veneno-remédio das culturas periféricas em Sérgio Buarque de Holanda, José Miguel Wisnik e Arcadio Díaz-Quiñones ${ }^{1}$
}

Pedro Meira Monteiro*

\section{Resumo}

0 espaço periférico engendra fantasias poderosas, capazes de converter a periferia num centro produtor de alternativas para os descaminhos do mundo moderno. Reagindo ao otimismo dessa visão, procuro flagrar três momentos da produção crítica moderna e contemporânea, no Brasil e no Caribe, em que os espaços periféricos parecem ter criado práticas sociais e culturais que resistem ao poder da norma. Para além de um elogio simplista das sociedades "híbridas" ou "mestiças", pretendo perguntar, com Sérgio Buarque de Holanda, José Miguel Wisnik e Arcadio Díaz-Quiñones, pela noção de sujeito que emerge das experiências marginais.

\section{Palavras-chave}

Sérgio Buarque de Holanda. José Miguel Wisnik. Arcadio Díaz-Quiñones. Culturas periféricas.

\begin{abstract}
Peripheralspaces can trigger powerful fantasies, which turn peripheryinto an imaginary source of alternatives for the modern world's derailment. By critically reacting to such optimism, my goal is to analyze three moments in Brazilian and Caribbean modern and contemporary critical thought in which those peripheral spaces seem to have engendered cultural and social practices capable of resisting the power of norms. Far beyond a naïve appraisal of "hybrid" societies, it is my purpose to inquire, along with Sérgio Buarque de Holanda, José Miguel Wisnik and Arcadio Díaz-Quiñones, about the notion of a political subject that emerges from marginal experiences.
\end{abstract}

\section{Keywords}

Sérgio Buarque de Holanda. José Miguel Wisnik. Arcadio Díaz-Quiñones. Peripheric cultures.

\footnotetext{
${ }^{1}$ Este texto é uma versão da "conferência magna" proferida durante o XIV Congresso da Associação Brasileira de Literatura Comparada (ABRALIC), em Belém, no dia 30 de junho de 2015.

* Pedro Meira Monteiro é Doutor em Teoria e História Literária pela Unicamp e Professor titular de Literatura Brasileira na Princeton University. E-mail: pmeira@princeton.edu.
} 


\section{Introdução}

Certo senso comum sugere haver semelhanças profundas entre países de tradição pós-colonial como Brasil e Cuba, onde o escravismo e a grande plantação são matrizes de formação de uma sociedade híbrida, em que a proximidade e o diálogo convivem com a exclusão e a violência. Conviria, entretanto, somar um pequeno território a esse mapa. Trata-se de Porto Rico, uma das ilhas mais ocidentais do Caribe, localizada ao lado da Hispaniola, a primeira grande ilha avistada por Colombo, onde hoje se encontram a República Dominicana e o Haiti. De Porto Rico vem a bela gravura da artista gráfica Consuelo Gotay, intitulada "A Arca de Noé", concebida na década de 1970 e inspirada nos poemas de Luis Palés Matos, “Los animales interiores".2

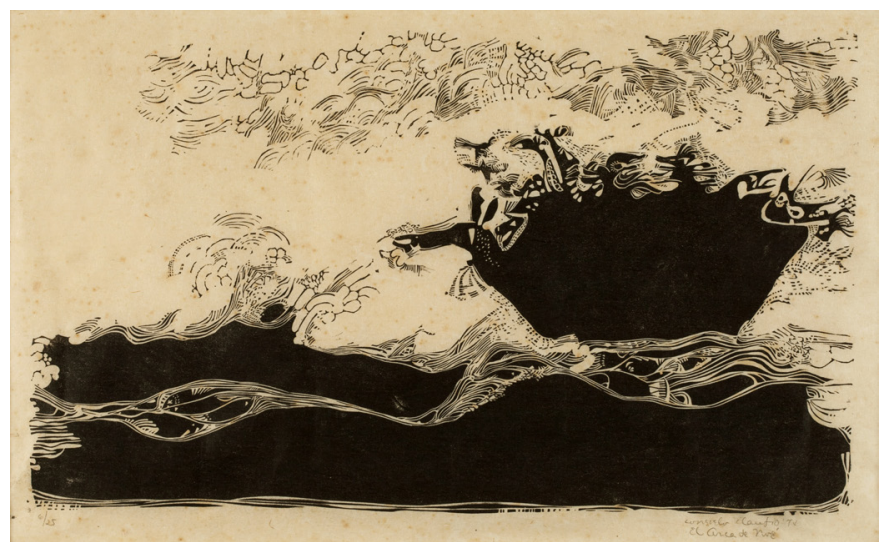

Mas antes ainda de percorrer esse mapa - imaginário, como todo mapa de leitura - faço um pequeno preâmbulo teórico e sentimental e parto de um incômodo. É intrigante que, ainda hoje, possamos nos flagrar defendendo as vantagens da periferia. Por que às vezes nos acreditamos melhores por não habitar aquilo que supomos ser o centro?

O mecanismo é muito conhecido, no plano psicológico: ao me sentir em perigo, invento um lugar em que a ameaça se desfaz. Tal sítio, afetivo e imaginário, pode coincidir com um lugar real, ou pode ser feito de nuvens.

\footnotetext{
${ }^{2}$ Agradeço a Consuelo Gotay a gentil permissão para reproduzir aqui a sua gravura.
} 
Trata-se de uma espécie de ventre original, onde me sinto protegido. A imaginação poética é pródiga em criar ventres originais.

O mesmo mecanismo de compensação simbólica funciona no plano cultural. No caso do Brasil, um antiamericanismo renitente se traduz, com frequência, na ideia de que o lado de lá, dos pioneiros protestantes e dos modernos homens e mulheres de negócios, é um mundo desencantado (MEIRA MONTEIRO, 2015; MORSE, 1988). "Eles" (os americanos) não têm jogo de corpo, são frios, calculistas, etc. Nesse jogo especular, a "nós", brasileiros, restaria a candura, o calor humano e a alegria. Uma boa análise sociológica e histórica desvanece imediatamente as fantasias bipolares, lembrando que a alegria e a candura mal escondem o classismo, o racismo, a incompetência e a corrupção, assim como, do outro lado, a frieza e a eficácia atribuídas aos norte-americanos ocultam a violência, a guerra, a vigilância, a exploração e toda uma tradição poética capaz, como nenhuma outra, de refletir sobre a solidão e a intimidade.

Ainda no plano cultural, como exemplo desse mecanismo de compensação simbólica, penso em Eduardo Lourenço, que se refere à forma como o cineasta alemão Wim Wenders identificou Portugal como "reserva do sonho" (LOURENÇO, 2001, p. 55-59). Nesse caso, a miséria pode ser escamoteada pela fábula de um tesouro oculto, que os portugueses insuspeitadamente guardariam. Tal tesouro periférico seria o "encantamento" que os outros europeus teriam perdido. $\mathrm{O}$ belo ensaio de Lourenço se refere à entrada de Portugal na União Europeia. No caso português, tanto melhor que o complexo de inferioridade tenha sido virado do avesso, e o futuro brilhante, quando o tesouro será reencontrado e plenamente gozado, tenha se convertido numa espera de largas consequências poéticas e políticas. Mas, com ou sem o Encoberto, diante da volta sempre protelada desse Rei que se perdeu nas areias do deserto, discute-se a provável vantagem de se habitar a periferia do mundo. É claro que o mito, no caso, oculta a violência colonial e pós-colonial.

Tais excursos devem servir para lançar uma sombra de suspeita sobre o sentimento de superioridade dos espaços periféricos. Mais que buscar as vantagens da periferia, ou mesmo a visão privilegiada dos seus intelectuais, valerá a pena perguntar o que as periferias, a um só tempo simbólicas e reais, produzem, no plano da vivência política. Que práticas engendram? Que técnicas do social, que pactos, que tipo de cultura política se desenvolve nesses espaços? E que fazer da rígida geografia que postula centro e periferia? Onde é mais cômodo estar? Numa periferia eternizada 
pela imaginação? Ou a prática política, por si só, desvanece a ilusão da periferia?

Pretendo, inicialmente, lembrar Sérgio Buarque de Holanda em Raízes do Brasil, ensaio em que se postula o conceito da "cordialidade", que funcionaria, segundo o crítico e músico José Miguel Wisnik, como um fármacon, ou um "veneno remédio" (HOLANDA, 2016; WISNIK, 2010). Por um lado, o homem cordial é supostamente capaz de estabelecer relações mais próximas com seus compatriotas, menos mediadas pelas regras frias da pólis. Por outro lado, essa mesma vantagem se converte em desvantagem, quando se trata de costurar a política no seu nível representativo, avesso ao personalismo mais estrito.

Num segundo momento, após discutir Sérgio Buarque de Holanda e José Miguel Wisnik, pretendo abordar uma palavra e um conceito de difícil tradução: o verbo bregar, que, na sua ductibilidade e riqueza semântica, mereceu um longo e iluminador ensaio do crítico porto-riquenho Arcadio Díaz-Quiñones (DÍAZ-QUIÑONES, 2016). Bregar, em poucas palavras, é negociar, avançar sabendo recuar, contornar quando necessário, resguardarse e furtar-se ao conflito quando preciso. É também uma forma de navegar o arriscado terreno da política em situações periféricas, quando o sujeito é um cidadão incompleto, dotado de direitos nem totalmente estabelecidos, nem totalmente esclarecidos, não poucas vezes ameaçados por uma máquina política ensanduichada entre o passado colonial e, no caso específico de Porto Rico, a presença avassaladora dos Estados Unidos.

A brega, em suma, guarda algumas semelhanças estruturais - poéticas e políticas - com a cordialidade. Ambas têm o potencial de nos desviar da dureza da lei, destinando o sujeito à negociação direta, com a possibilidade de atenuar conflitos. Nesse sentido, a cordialidade e a brega são instrumentos regeneradores, como um remédio que vertesse sobre o tecido social. Mas, ao mesmo tempo, os dois instrumentos se convertem facilmente em veneno, porque, cada qual a seu modo, podem manter o sujeito num plano em que ele se furta ao choque, mantendo-se no restrito círculo de possibilidades que a sociedade de raízes coloniais e escravistas lhe oferece. No entanto, como veremos logo mais, a brega não é apenas evasiva. Há nela algo de propositivo, que se encontra menos presente, talvez, na cordialidade.

$$
* * *
$$


Comecemos pela cordialidade. O conceito, que aparece em $1936 \mathrm{em}$ Raízes do Brasil e é depois largamente retrabalhado para a segunda edição do livro, de 1948, foi criado por Sérgio Buarque de Holanda a partir de uma observação feita pelo poeta Rui Ribeiro Couto em correspondência com Alfonso Reyes, então embaixador do México no Brasil. A propósito, as raízes latino-americanas de Raízes do Brasil permitem notar que o "homem cordial" é uma expressão longeva, tendo figurado, talvez pela primeira vez numa língua ibérica, na referência do poeta nicaraguense Rubén Darío ao argentino Saenz Peña, antes ainda que este se tornasse presidente da Argentina, o que revela uma rica trama finissecular ibero-americana como pano de fundo de Raízes do Brasil (MEIRA MONTEIRO, 2015, p. 117-140). Além disso, os diálogos "interamericanos" que sustentam a imaginação das "raízes" do Brasil foi estudado, há alguns anos, por Robert Patrick Newcomb, num estudo em que o jovem Sérgio Buarque de Holanda é classificado como uma possível "lost child of Rodó", numa referência ao amplo debate do arielismo nos círculos intelectuais latino-americanos (NEWCOMB, 2012).

Seja qual for a genealogia da expressão "homem cordial", na sua origem está a imaginação de uma possível vantagem latino-americana sobre os prósperos Estados Unidos da América. Na leitura do escritor uruguaio José Enrique Rodó, Ariel, o gênio do ar, personagem de A tempestade, posta-se contra a ganância de Próspero, que governa a ilha imaginada por Shakespeare na aurora do colonialismo. Há que lembrar que Rodó vê os Estados Unidos com um misto de admiração e, sobretudo, desprezo, imputando-lhe uma insuportável combinação de materialismo e arrivismo (RODÓ, 2004).

Bem mais tarde, já na onda do desrecalque localista dos anos 1960, é Caliban quem surge, ressignificado pelas lutas pós-coloniais, como uma saudável ameaça à arrogância e à neurose dominadora de Próspero. Mas em todos os casos, dos arielistas de fim de século aos calibanistas dos libertários anos 1960, trata-se de uma resposta ao poder e à gana dos Estados Unidos.

Voltemos, contudo, ao homem cordial. Sabe-se que a leitura da cordialidade prevalecente não é a de Sérgio Buarque de Holanda, mas sim a de Ribeiro Couto e a de Cassiano Ricardo, poeta e intelectual orgânico do Estado Novo (MEIRA MONTEIRO; SCHWARCZ, 2016). Para eles, e para muitos outros, nos dias de hoje, a cordialidade resume qualidades positivas: a bondade, a lhaneza, a proximidade com o outro, o calor humano, etc. São todas qualidades presentes não só em Raízes do Brasil, 
mas também latentes na grande matriz interpretativa de Gilberto Freyre, para quem a dura dominação colonial teria sido "amaciada" pelo "óleo da mediação africana", numa tese que, surgida na década de 1930, faria história, pendendo consideravelmente para a direita nas décadas seguintes. Contudo, se o luso-tropicalismo freyriano dos anos 1950 e 1960 encontrou guarida no imaginário salazarista, seria empobrecedor reduzir obras do porte de Casa-grande \& senzala e Sobrados e mucambos, concebidas na década de 1930, a um laivo puramente reacionário (BENZAQUEN, 1994).

Se lemos Raízes do Brasil, encontramos, lá também, caraterísticas inequivocamente positivas do brasileiro:

"Já se disse, numa expressão feliz, que a contribuição brasileira para a civilização será de cordialidade - daremos ao mundo o 'homem cordial'. A lhaneza no trato, a hospitalidade, a generosidade, virtudes tão gabadas por estrangeiros que nos visitam, representam, com efeito, um traço definido do caráter brasileiro, na medida, ao menos, em que permanece ativa e fecunda a influência ancestral dos padrões de convívio humano, informados no meio rural e patriarcal".

(HOLANDA, 2016, p. 254)

Não me estendo sobre a senda, ou antes a larga avenida, que tal passagem abre no pensamento social brasileiro. Lembro apenas que, desde os românticos, no século XIX, até algumas das chamadas interpretações "modernistas" do Brasil, a chave explicativa se encontrava em questões como a felicidade ou a tristeza. O Brasil, em suma, se via diante da tarefa de guardar a alegria do mundo, ou então diante da constatação melancólica de sua incapacidade para a civilização. Se os retratos do Brasil se projetam sob a sina da alegria e da tristeza, talvez até hoje o país seja vítima de um lugar imaginário, presa de uma "promessa de felicidade", como a chamou José Miguel Wisnik, pensando no poder sintético da bossa nova, no contexto nacional-desenvolvimentista da década de 1950 no Brasil (WISNIK, 2004, p. 213-239). No caso específico da cordialidade, ela se torna incompreensível sem a sombra de uma crônica incapacidade civilizatória. De um lado, promessa; de outro, descalabro.

A incapacidade civilizatória se condensa num impasse, que Sérgio Buarque de Holanda vai buscar na tragédia grega. Amparado numa leitura hegeliana de Sófocles, o ensaísta vê, no conflito entre Creonte e Antígona, a chave para a compreensão da formação do espaço público. Recordemos a 
célebre passagem:

“O Estado não é uma ampliação do círculo familiar e, ainda menos, uma integração de certos agrupamentos, de certas vontades particularistas, de que a família é o melhor exemplo. Não existe, entre o círculo familiar e o Estado, uma gradação, mas antes uma descontinuidade e até uma oposição. [...] Só pela transgressão da ordem doméstica e familiar é que nasce o Estado e que o simples indivíduo se faz cidadão, contribuinte, eleitor, elegível, recrutável e responsável, ante as leis da Cidade. [...] Ninguém exprimiu com mais intensidade a oposição e mesmo a incompatibilidade fundamental entre os dois princípios do que Sófocles. Creonte encarna a noção abstrata, impessoal da Cidade em luta contra essa realidade concreta e tangível que é a família. Antígona, sepultando Polinice contra as ordenações do Estado, atrai sabre si a cólera do irmão [sic], que não age em nome de sua vontade pessoal, mas da suposta vontade geral dos cidadãos, da pátria".

(HOLANDA, 2016, p. 245-246)

O Estado aqui é uma transcendência virtuosa, capaz de superar o espírito particularista da família, fundando a ética pública, a qual, na imaginação de Hegel, é simbolizada pelo irmão. Na Fenomenologia do Espírito, o irmão é aquele que deixa a casa e ocupa o espaço público, enquanto a irmã resguardaria os valores privados e os afetos, no âmbito da família (HEGEL, 1992, p. 18-26). Deixada apenas à sorte da irmã (Antígona), a cidade se torna espaço de realização dos laços familiares, embora, de uma perspectiva estritamente hegeliana, o Direito público, encarnado por Creonte, termina por ser desrespeitado.

Deixo de lado a violência dessa leitura de Hegel de que é vítima o próprio Sérgio Buarque de Holanda, que não à toa confunde o parentesco de Creonte e Antígona, considerando-os irmãos, quando, na verdade, são tio e sobrinha. Atenho-me apenas ao fato de que a tensão entre a família e o Estado se traduz numa prática política determinada, ou seja, numa cultura de relações e num horizonte de expectativas sobre a formação - ou mais propriamente sobre a de-formação - do espaço público. A confusão entre as esferas do público e do privado é tema muito antigo no pensamento social brasileiro e, como bem se sabe, encontra tradução quase imediata nas práticas cotidianas de invasão e desrespeito do espaço público - males, não custa nada lembrar, que atravessam as classes sociais. 
Aquela idealizada e louvável atitude "aberta" e "calorosa" dos brasileiros inaugura então um paradoxo: ao viver as relações políticas como relações pessoais, aproximando-se do Outro sem as mediações do protocolo e da reverência, o homem cordial é incapaz de portar as máscaras da representação política. Afinal, no terreno da pólis, ordenado pelo zelo de Creonte (reinterpretado e valorizado por Hegel), todos seriam cidadãos, portadores dos mesmos direitos. Levando a questão ao limite, tal é o paradoxo da igualdade: promovida a equalização, abolemse as preferências e as repugnâncias, para que se desmontem também as hierarquias de sangue. No entanto, as linhagens e a hierarquia de sangue não são apenas o produto do Antigo Regime. Para "amar", sugere Sérgio Buarque, é preciso escolher e preferir uns sobre os outros.

O homem cordial, em Raízes do Brasil, não é apenas bondoso, nem mesmo afável. Diante da impessoalidade da lei geral, ele está sempre prestes a criar uma lei própria, um privilégio em potencial, dando vazão ao puro arbítrio do sujeito. Aqui se explica, ademais, a sobranceria como característica do "homem ibérico", no início de Raízes do Brasil. É verdade que, escorados em Kafka e Agamben, sabemos que a lei sempre é arbítrio. No entanto, no quadro do pensamento liberal em que se inscreve Raízes do Brasil, há uma diferença entre a lei geral, da pólis, e a lei privada, da família. Para essa imaginação, sempre que o Direito for moldado pela vontade particularista da família, corre-se o risco de que o tecido político seja rompido, ou de uma perspectiva ainda liberal - corre-se o risco de que o monstro do autoritarismo mostre sua cabeça.

Numa leitura radicalmente liberal, o "homem cordial" seria uma ameaça à formação do espaço público, em que as diferenças, idealmente, são resolvidas por um jogo de máscaras. A representação, no caso, determina papéis e marca a impossibilidade de acolher ou proteger o Outro diretamente, sem mais mediações, como se ele fosse um amigo ou irmão. Levando tal retrato da política ao seu extremo, o político liberal, imune a beijos ou à imersão no corpo místico da coletividade, seria pura máscara, protegida contra o sangue e os afetos. A cordialidade se reafirma então como benfazeja, quando se trata de devolver, às relações humanas, seu lastro afetivo e pessoal, tornando-se, entretanto, lesiva, quando o lastro dessas relações não deixa que a pessoa se apague diante do cidadão, o que marca uma larga reflexão sobre o espaço público no Brasil, que tanto rende para a crítica universitária e jornalística. Mas quem é o cidadão senão aquele que, ao resguardar-se do arbítrio das relações pessoais, guardou a 
lei dentro de si?

A internalização da lei é o grande tema de Sérgio Buarque de Holanda. Contudo, a interiorização da norma é o outro lado da moeda de um insistente elogio dos espaços não regrados, que se furtam ao centro da lei, isto é, que sabem contornar a tirania da regra. É como se as práticas geradas em espaços periféricos dependessem, justamente, de um jogo sinuoso com a lei, ocultando-se diante dela, quando necessário, e criando uma zona cinza em que a letra da lei é um dito e um não dito, um ser e não ser simultâneos. Na interessante imagem de Altair Martins, trata-se de uma "civilização do atalho" (MARTINS, 2014).

$$
* * *
$$

Recapitulando, a cordialidade é tão boa quanto ruim, deixandose compreender plenamente se tomarmos em consideração um debate candente à época em que se gerou Raízes do Brasil: a tensão entre a ordem e a desordem. Sabemos que o elogio da desordem e o desapego à norma grassam na tradição literária e no pensamento no Brasil. Os exemplos são inúmeros, e o próprio Sérgio Buarque de Holanda não esteve imune a esse veneno, ou talvez a esse remédio. A propósito, quando José Miguel Wisnik analisou a experiência brasileira à luz do futebol, em Veneno remédio: o futebol e o Brasil, o que estava em questão, em seu diálogo com o autor de Raízes do Brasil, era justamente o balanço entre a ordem e a desordem. Tal balanço teria dado forma a um dos primeiros romances da literatura brasileira, as Memórias de um sargento de Milícias, de Manuel Antonio de Almeida. Contudo, sabemos que a interpretação da forma desse balanço entre ordem e desordem se deve a Antonio Candido, grande amigo e editor de Sérgio Buarque de Holanda, e orientador de José Miguel Wisnik na Universidade de São Paulo. Mas deixemos as genealogias de lado.

Em traços esquemáticos, Antonio Candido viu, no romance do século XIX, um balanço irresolvível entre a ordem cívica e a desordem lúdica, como se o nosso herói vivesse entre esses dois polos, incapaz de estacionar num deles. O que o crítico tira dessa fórmula é um resultado surpreendente, porque o polo da desordem, isto é, do desvio em relação à lei geral, acaba por ganhar acento positivo, dentro daquilo que se cunhou, celebremente, como a "dialética da malandragem". Para compreender tal passo, convém ouvir o próprio José Miguel Wisnik e perceber que a imagem do Brasil que aí se forja parece requerer o outro lado do espelho de Próspero. Isto é, a 
projeção do Brasil depende da imagem reversa dos Estados Unidos:

“Foi exatamente isso que Antonio Candido viu no livro [de Manuel Antonio de Almeida], de cuja análise extraiu [...] uma interpretação de surpreendente acento positivo: sua atmosfera produziria um encantador 'mundo sem culpa' de ânimo democrático e tolerante, avesso a estigmatizações e caça a bruxas. [Candido] compara o caráter excludente de sociedades puritanas, como a norte-americana monorracial e monorreligiosa (onde a forte introjeção da lei endureceria o indivíduo e o grupo, conferindo certa identidade e resistência, mas desumanizando as relações), com o caráter potencialmente dialógico e aberto da sociabilidade espontânea no Brasil (onde o abrandamento dos choques entre a norma e a conduta desafogaria os conflitos de consciência permitindo maior aceitação do outro). Assim, naquele momento de ditadura em que foi escrito o texto [1970], a 'dialética da malandragem' (e o decorrente 'mundo sem culpa' ao qual está associada) aparece a Antonio Candido como vantagem sobre a ética protestante e o espírito do capitalismo e como um 'trunfo para a hipótese de nos integrarmos num mundo mais aberto' (conforme a resenhou Roberto Schwarz). Inspirado pela leitura das Memórias de um sargento de milícias, Antonio Candido opta, pois, pela tônica afirmativa da ambivalência sérgio-buarquiana e introduz no paradigma uspiano um inusual elogio das peculiaridades brasileiras natas".

(WISNIK, 2010, p. 424)

É preciso entender o laboratório em que Wisnik testa e compõe as ideias. Ele vinha se referindo, em seu livro, a uma espécie de tríptico da interpretação do Brasil, composto, em primeiro lugar, pela visão crítica e ácida de Caio Prado Jr. sobre a colonização portuguesa na América; em segundo lugar, pela visão edulcorada e feliz da malemolente civilização tropical em Gilberto Freyre; e, finalmente, como um terceiro e indecidível termo, nem veneno nem remédio, nem solução nem descalabro, nem futuro glorioso nem fim do mundo, surge a "ambivalência sérgio-buarquiana", operando como o "fármacon" a que se referiria, em chave distinta, Jacques Derrida (MEIRA MONTEIRO, 2015, p. 179-199).

Há um detalhe adicional, fundamental na geografia afetiva e ideológica na qual se inscreve o próprio Wisnik. Quando fala num "paradigma uspiano", ele está se referindo à presença soberana de Caio Prado Jr. na interpretação da sociedade brasileira, compreendida como ainda atada a suas raízes coloniais, oferecendo farta matéria para a análise que 
prevaleceria nos corredores da Universidade de São Paulo, embora não só ali, a partir das décadas de 1950 e 1960:

"Sob o realismo minucioso e implacável do seu crivo produtivista, Caio Prado Júnior não vê lugar para o despontar de alguma produção cultural original. [...] Reconhecemos na [sua] visão não só uma perspectiva individual, mas também a fundação de um paradigma de abordagem do Brasil, com a sua linhagem crítica correspondente, na qual tem um lugar central a sociologia paulista e uspiana. Nesta, a ênfase recairá na identificação do atraso e do deslocamento brasileiro na ordem mundial, sem privilégio para originalidades culturais populares, consideradas pouco relevantes no quadro econômico e político. O diagnóstico produzirá uma teoria da dependência e uma análise da condição periférica [claras referências a Fernando Henrique Cardoso e Roberto Schwarz]. Se aplicado ao futebol, investe o seu tônus desmistificador na análise das condições socioeconômicas que cercam o esporte, sem chance para a contemplação de redentoras 'gingas' e 'jeitos de corpo' - e sem atribuir relevância à singularidade da imbricação cultural". (WISNIK, 2010, p. 409-411)

Em suma, a "ambivalência sérgio-buarquiana" é injetada na máquina da interpretação, de modo a desemperrar o seu desenvolvimento ciclotímico, que oscilava entre a solução freyriana, no polo positivo, e a solução caiopradiana/uspiana, no polo negativo. Somente aí compreendemos a presença de Antonio Candido como orientador de um novo caminho, ao destacar em Sérgio Buarque de Holanda aquela inclinação à desordem que faz, do homem cordial, alguém que dribla a lei, como Garrincha ou Pelé driblavam um adversário inoportuno.

A questão, aqui apenas apontada, é que, em Veneno remédio, Wisnik não forma nas fileiras freyrianas, embora o seu "tropicalismo" insista, teimosa e alegremente, em manusear a ambivalente poção buarquiana, recusandose a ver, na postura solta diante da técnica, algo como uma incompetência crônica diante do mundo moderno. ${ }^{3}$ Como se, em bom estilo ensaístico,

\footnotetext{
${ }^{3}$ A questão regressou, em chave polêmica, nas investidas recentes de Jessé Souza, que atribui a Sérgio Buarque de Holanda a criação de uma tradição "colonizada até o osso", supostamente limitada a uma matriz interpretativa que não leva em conta os contextos "institucionais e históricos da ação social" (SOUZA, 2015).
} 
sua análise protelasse indefinidamente o momento de cristalização de uma fórmula. Se atentarmos para o título de seu livro (Veneno remédio), tudo fica em suspensão, como uma pergunta que não cala, ou como a fórmula incompleta de uma poção que ainda não foi chacoalhada até o final.

A questão, insisto, está na relação com a lei e na possibilidade de oscilar diante dela, enfrentando-a obliquamente, ou então simplesmente se desviando dela, pegando talvez o "atalho" de Altair Martins, que é também, diga-se de passagem, o atalho da própria ficção.

Pensando no plano linguístico - simultaneamente poético e político -, esteé o momento próprio para lembrar a brega. Numa primeira aproximação, a brega, como a vê Arcadio Díaz-Quiñones, é "um método difuso e sem alarde para navegar a vida cotidiana, onde tudo é extremamente precário, cambiante ou violento". Essa é a primeira das muitas definições provisórias com que o sentido da brega é cercado, levando àquilo que o crítico vai nomear, não sem um misto de admiração e ironia, "a arte de bregar". ${ }^{4}$

Valho-me aqui de minha própria tradução ao português, que sintomaticamente empaca diante da palavra que dá título ao ensaio: bregar. O equivalente em português, brigar, manteve da origem etimológica - que do italiano antigo brigare leva a incertas origens celtas - apenas o sentido de afrontar e lutar, enquanto no léxico insular de Porto Rico e de certas regiões do Caribe hispanófono, bem como em Nova York e nas grandes cidades da diáspora porto-riquenha, a expressão bregar ganhou espessura e se tornou signo de uma luta a meias, ou de algo que eu traduziria como a "arte de furtar-se", brincando com o título polêmico da obra luso-brasileira que foi um dia atribuída erroneamente ao Padre Vieira, A arte de furtar. Traduziria, não fosse o fato de que bregar pode significar tanto evitar o conflito, quanto, ao mesmo tempo, indicar o reconhecimento efetivo do momento em que o sujeito deve se impor. A arte de bregar não é, portanto, puramente evasiva. Ela é quase sempre elíptica, mas não é simples retraimento. Em suma, o

\footnotetext{
${ }^{4}$ Retomo aqui, adaptando-a, a introdução que escrevi para A memória rota (DÍAZ-QUIÑONES, 2016).
} 
sujeito da brega não se furta à luta. Não se trata, portanto, de uma simples arte de furtar-se.

A brega pode ser vista como uma sutil e complexa técnica de navegação nas águas de uma sociedade de raízes coloniais, que sistematicamente recusa um lugar claro para a maioria de seus cidadãos, cuja cidadania, aliás, é um problema irresolvível, como bem sugere o estatuto de Porto Rico como "Estado Livre Associado", ou "Commonwealth" dos Estados Unidos.

No ensaio sobre a arte de bregar, intitulado "De como e quando bregar", logo de início, a brega se anuncia como uma arte da negociação de sentidos, espécie de dispositivo que cria ambivalências, exigindo, portanto, uma nova decifração do seu significado a cada novo contexto em que ela se insere:

“Diante da saudação ritual e cortês, 'Cómo estás [como vai?]',
muitos porto-riquenhos respondem lacônica ou brincalhonamente
com uma frase aprendida que parece um mote a glosar: 'Aquí, en
la brega [Aqui, na brega]'. Não é uma forma de ser. É uma forma
de estar e não estar, um tipo não preciso de luta, uma negociação
entre a ausência e a presença. Há situações que se consideram
pouco propícias ou impossíveis, e então o tom muda e se escuta a
frase: Yo con eso no brego [Eu com isso não brego]".
(DÍAZ-QUINONONES, 2016, p. 38)

Há limites para a brega, e desde já fica claro que ela não tem a pretensão de encerrar o "caráter nacional" de uma coletividade, cujo estatuto nacional, aliás, se encontra em suspenso há muito tempo, como no caso de Porto Rico.

Outra palavra de difícil tradução - central para a discussão da brega -, que mereceu uma nota explicativa na tradução que fiz do ensaio de DíazQuiñones, é cimarrón. Cimarrón, ou cimarrones, refere-se fundamentalmente aos fugitivos, e a palavra poderia ser entendida, talvez, como equivalente do português quilombola, ou seja, o habitante do quilombo, ou daquilo que no Caribe hispânico viria a chamar-se palenque. Em termos bem amplos, é também uma referência a espaços não inteiramente regulados, ou com uma regulação própria, gerados historicamente numa sociedade na qual a presença de piratas, contrabandistas e escravos tornava central a figura do fugitivo. O cimarrón, nesse sentido, contém toda a história do encontro de europeus, nativos e africanos no espaço insular do Caribe.

Ressalto ainda que os ensaios de Arcadio Díaz-Quiñones têm a música e a poesia como um sutil pano de fundo, e a arte de bregar é também uma arte da fuga - em mais de um sentido. Talvez mesmo pudéssemos dizer que a 
forma ensaística, quando levada à sua máxima altura, nos faz recordar que é impossível pensar sem utilizar contrapontos. A sociedade, nesse duplo sentido, é uma invenção a várias vozes. Como uma tecnologia complexa que jamais tivesse ganhado um manual de instruções, a arte de bregar é definida ainda como uma "metáfora estratégica", no sentido que lhe atribui Kenneth Burke: uma ação capaz de mover aquele que escuta. O aspecto dialógico da brega é fundamental e, não à toa, Arcadio Díaz-Quiñones evoca William James, Ludwig Wittgenstein, Mikhail Bakhtin, Erving Goffman, Luis Palés Matos, Hannah Arendt, o mítico jogador de baseball Victor Pellot (ou Vic Power), Judith Ortiz Cofer, e mesmo Luis Muñoz Marín, o governador "populista" de Porto Rico, todos convocados a dizer algo sobre o caráter "contingente" que torna a brega - e a própria linguagem - o palco por excelência da luta política.

Resta refletir sobre o caráter dessa luta. Sendo contingente, situacional, transitória, como que flutuando em torno da lei - siderada por ela, sendolhe ao mesmo tempo resistente -, a brega é, como se lê no ensaio, a arte do "não trágico", ou do "não épico". São lutas, mas lutas diárias e silenciosas, que ganham expressão em gestos mínimos, muitas vezes decisivos e cheios de sentido, mas quase nunca capazes de se estabilizar numa gesta heroica. Trata-se de uma poética da resistência, feita de negociações sutis e muitas vezes inconscientes, permitindo pensar num paralelo com aquilo que Alfredo Bosi chamou de "dialética da colonização" (BOSI, 1992). Isto é, do seio da relação de dominação, e sem que as posições de dominado e dominador necessariamente se alterem, surge a voz de um "Outro", destinada a se atualizar no plano oral, eventualmente passível de ser estilizada na literatura. Como se a virtualidade do sujeito exposto à "condição colonial" se atualizasse nesses momentos frágeis e irrepetíveis que marcam a resistência, ou, em termos de sabor gramsciano, seriam esses momentos de realização propriamente contra-hegemônica.

Não me estendo sobre a presença dos poemas de Luis Palés Matos na imaginação ensaística de Arcadio Díaz-Quiñones. Lembro, no entanto, do verdadeiro desespero deste tradutor diante do ten-con-ten de Palés, uma expressão rara e explosiva, que se poderia compreender como afirmação da delicadeza, mas também como um "balanço" e um negaceio. Aliás, "ginga" seria uma boa tradução para ten con ten, não fosse o fato de que a ginga se associa frequentemente, no Brasil, a uma noção edulcorada da "bossa" como traço nacional e essencial. Em suma, creio que o léxico da capoeira, ou mesmo do futebol, acabaria pondo a perder o aspecto dialógico que está no 
texto de Díaz-Quiñones. Exagerando um pouco nas tintas, é possível supor que o vocabulário da capoeira e do futebol, em que se contemplam a ginga e o jeito, foi "sequestrado" pela ideologia do Estado Novo, apontando para o caráter não violento que é apenas uma face, talvez nem mesmo a mais importante, daquilo que a arte de bregar propõe.

A brega, mesmo quando contempla a retirada e o desvio, a elipse e o drible, carrega uma espécie de proposição, ou de sentido positivo, que está na manutenção delicada, nem trágica nem heroica, da vida. É uma batalha contra a guerra, ou contra a morte do sujeito. Trata-se de um sujeito, o da brega, que se equilibra - tão humana e dignamente quanto possível - na corda bamba das relações assimétricas. Quem brega sabe estar jogando com um adversário mais forte: as instituições, o preconceito, o racismo, as barreiras de gênero, a própria linguagem. Em português, poderíamos dizer que somente brega aquele - ou aquela - que brinca com o perigo, porque conhece a força do inimigo e sabe que só pode dobrá-lo à custa de gestos muitas vezes ambíguos, cujo sentido é resvaladiço. Quem brega não quebra as estruturas nem rompe o tecido social, mas aprende a respirar, numa navegação complexa e arriscada.

$$
* * *
$$

Para finalizar, reforço a ideia de que é a noção do sujeito, especificamente do sujeito político, que se discute por meio de palavras como a cordialidade e a brega. Nos dois casos, o sujeito se afirma exatamente quando explora o espaço aberto por suas próprias limitações. No caso da brega, seu poder está, paradoxalmente, na exploração dos limites impostos por sua própria impotência, e na compreensão, não apenas no plano racional, da força maiúscula daquilo que o determina. Não à toa, o diálogo com a psicanálise está sempre latente, quando se trata da brega. Já o "homem cordial" carrega uma ambivalência perversa, porque, ao mesmo tempo em que insiste em ser promessa, ele encerra um círculo vicioso: quando referido à posição dominada, o lastro pessoal acaba por jogá-lo para baixo, e ele dificilmente se ergue diante do Outro que o aplasta; quando referido à posição dominante, o homem cordial expressa a cegueira diante do Outro, uma vez que a lei só serve para o círculo de apaniguados, deixando de fora os que não aceitam o alto preço da sua proteção nem sempre benigna.

O sujeito da brega, poderíamos talvez dizer, nem sempre se encolhe diante do espaço público. Ele (ou ela) mede o terreno e arrisca com sabedoria. $\mathrm{Ou}$ 
seja, joga com o território que lhe é familiar, mas nunca se entrega àquilo que é completamente desconhecido. Seu avanço é feito de sucessivos recuos e desvios, de movimentos que resistem a um desenho claro. Insisto que se trata de um dispositivo de ambivalência, com um fundo propositivo, quase sempre. Nesse quase reside o aspecto trágico de uma forma de lutar que por vezes se torna um verdadeiro mecanismo de defesa:

\begin{abstract}
"Em Chicago ou na ilha, a concisa expressão hay que bregar [tem que se bregar] pode ser uma exortação a produzir ideias e iniciativas, inclusive com certa militância, com o fim de confrontar políticas, condutas e desafios técnicos. No entanto, em outro contexto, e como outras duplicidades da vida porto-riquenha, pode ser uma frase morta que se diz para desconectar-se e manter as aparências, uma frase que nem começa nem termina, e que apenas gira sobre si mesma. Interessa essa brega não épica, que permite seguir adiante com a vida por conta da necessidade de salvar algo do naufrágio".
\end{abstract}

(DÍAZ-QUIÑONES, 2016, p. 68-69)

Para aqueles de nós que estamos para cá da fronteira imaginária que nos separa dos heróis, convém entender que a expressão do desejo do sujeito dominado é sempre, pela própria razão da sobrevivência, uma afirmação a meias, negociada no tecido às vezes duro, às vezes macio, das relações sociais.

Pensando nas dinâmicas da política, convém discutir o fato decisivo de que, mesmo e sobretudo no plano social, a realização do desejo é sempre uma fantasia fadada ao fracasso. Afinal, o desejo vive no intervalo entre a virtualidade da promessa e a atualidade de um caminho possível. Num resumo apertado, tanto o homem cordial quanto o sujeito da brega vivem nesse caminho incompleto, que é o de uma política do desejo. Entretanto, os que concebem a política como vitória vão supor que esse "meio do caminho" é apenas a desculpa para um desejo falhado, como se o sujeito que se afirma a meias fosse um incapaz.

No entanto, o que se está dizendo aqui é que a potência do sujeito está exatamente na sua maior ou menor capacidade de se afirmar

${ }^{5}$ Díaz-Quiñones, Arcadio. A memória rota, op.cit. 
incompletamente. Os que concebem a política como a arte da vida talvez possam recordar, com Sérgio Buarque de Holanda, José Miguel Wisnik e Arcadio Díaz-Quiñones, que o desejo é uma ponte tesa e instável que só existe no momento em que é percorrida. Não se trata de alcançar o remédio no fim da ponte, nem de engolir o veneno de um caminho áspero, mas de encontrar um modo de vida, e talvez um novo conceito do político, entre os dois.

O sujeito, em suma, avança exatamente quando recusa a épica da ação, mergulhando-a no tempo instável da vida real. Só assim nos salvamos do naufrágio, levando o que conhecemos do velho mundo, deixando-o um pouco para trás, para que a história se inicie, de novo, a cada dia

\section{Referências}

BENZAQUEN DE ARAÚJ0, Ricardo.

(1994). Guerra e paz: Casa-grande \& senzala e a obra de Gilberto Freyre nos anos 30. Rio de Janeiro, Editora 34.

BOSI, Alfredo.

(1992). Dialética da colonização. São Paulo, Companhia das Letras.

DÍAZ-QUIÑONES, Arcadio.

(2016). A memória rota: ensaios de cultura e política. Trad. Pedro Meira Monteiro. São Paulo, Companhia das Letras.

HEGEL, Georg W. F.

(1992). Fenomenologia do Espírito. Trad. Paulo Meneses. Petrópolis, Vozes.

HOLANDA, Sérgio Buarque de.

(2016). Raízes do Brasil. Ed. crítica, org. Pedro

Meira Monteiro, Lilia Moritz Schwarcz. São

Paulo, Companhia das Letras.

LOURENÇO, Eduardo.

(2001). A Nau de Ícaro e Imagem e miragem da lusofonia. São Paulo, Companhia das Letras.

MARTINS, Altair.

(2014). Terra avulsa. Rio de Janeiro, Record.
MORSE, Richard M.

(1988). 0 espelho de Próspero: cultura e ideias nas Américas. Trad. Paulo Neves. São Paulo, Companhia das Letras.

MEIRA MONTEIRO, Pedro.

(2015). Signo e desterro: Sérgio Buarque de Holanda e o Brasil. São Paulo, Hucitec / e-galáxia.

MEIRA MONTEIRO, Pedro; SCHWARCZ, Lilia Moritz (Orgs.).

(2016). Uma edição crítica de Raízes do Brasil: o historiador lê a si mesmo. In: Sérgio Buarque de Holanda; Raízes do Brasil. São Paulo: Companhia das Letras. p. 11-26.

NEWCOMB, Robert P.

(2012). Nossa and Nuestra América: InterAmerican Dialogues. West Lafayette, Purdue University Press.

RODÓ, José Enrique.

(2004). Ariel. Madrid, Cátedra.

SOUZA, Jessé.

(2015). A tolice brasileira: ou como o país se deixa manipular pela elite. São Paulo, Leya. E-book. 
WISNIK, José Miguel.

(2010). Veneno remédio: o futebol e o Brasil. São Paulo, Companhia das Letras.

(2004). Sem receita: ensaios e canções. São Paulo, Publifolha.

\section{Recebido em}

abril de 2017

Aprovado em

maio de 2017 